\title{
PAPEL DOS GESTORES NA MUDANÇA CULTURAL DA ADMINISTRAÇÃO CENTRAL DO ESTADO: O CASO DA MERITOCRACIA
}

\section{PAPEL DE LOS GESTORES EN EL CAMBIO CULTURAL DE LA ADMINISTRACIÓN CENTRAL DEL ESTADO: EL CASO DE LA MERITOCRACIA}
MANAGERS' ROLE IN THE CULTURAL CHANGE TO HAVE OCCURRED WITHIN PORTUGUESE PUBLIC ADMINISTRATION: THE CASE OF MERITOCRACY

\author{
LE ROLE DES GESTIONNAIRES DANS LE CHANGEMENT CULTUREL DE \\ L'ADMINISTRATION PUBLIQUE AU PORTUGAL : LE CAS DE LA MERITOCRATIE
}

管理者在国家中央行政文化的变化中的作用: 能人统治研究

DOI: 10.5533/1984-2503-20135202

João Bilhim ${ }^{1}$

\section{RESUMO}

A influência da New Public Management (NPM) na reforma administrativa em Portugal e, em particular, no que toca à introdução de maior racionalidade técnica nos processos de gestão pública é amplamente reconhecida (Mozicafredo, 2000); (Bilhim, 2008); (Rocha, 2011). Foram muitos os governos que, nos países da OCDE, tomaram iniciativas idênticas. Todavia, a literatura sobre a reforma administrativa apresenta bastante evidência da resiliência das burocracias institucionais ao controlo dos gestores e à mudança (Burns e Stalker, 1961); (Bjur e Caiden, 1978); (Bilhim 1995, 2010). Por outro lado, a sociologia da gestão tem ajudado a identificar e compreender a imagem platónica do gestor - executor racional do sistema de planificação e controlo de uma estrutura organizacional, adaptável rapidamente à envolvente - transmitida pela retórica da ideologia tecnocrata (Reed, 1989). Este artigo quer contribuir para o debate sobre o papel do gestor público na mudança da cultura organizacional, a partir do caso da meritocracia. Palavras-chave: Cultura Organizacional, Gestão Pública, Mudança Organizacional.

\footnotetext{
${ }^{1}$ Doutor em Ciências Sociais pela Universidade Técnica de Lisboa (UTL) (1993). Atualmente é presidente da Comissão de Recrutamento e Seleção da Administração Pública. Professor catedrático da Universidade Técnica de Lisboa; investigador do Centro de Administração e Políticas Públicas CAPP/ ISCSP/UTL.

E-mail: bilhim@iscsp.utl.pt
} 


\section{RESUMEN}

La influencia de la New Public Management (NPM) en la reforma administrativa en Portugal y, en particular, en lo que se refiere a la introducción de una mayor racionalidad técnica en los procesos de gestión pública está ampliamente reconocida (Mozicafredo, 2000); (Bilhim,2008); (Rocha, 2011). Muchos fueron los gobiernos que, en los países de la OCDE, tomaron medidas idénticas. Todavía hoy, la literatura sobre la reforma administrativa muestra muchas evidencias de la resiliencia propia de las burocracias institucionales al control de los gestores y a los cambios (Burns e Stalker, 1961;Bjur e Caiden, 1978; Bilhim 1995, 2010). Por otra parte, la sociología de la gestión ha contribuido a identificar y comprender la imagen platónica del gestor - ejecutor racional del sistema de planificación y control de una estructura organizativa, adaptable rápidamente al entorno - transmitida por la retórica de la ideología tecnócrata. Este artículo pretende contribuir al debate sobre el papel del gestor público en el cambio de la cultura organizacional a partir del caso de la meritocracia.

Palabras clave: Cultura Organizacional, Gestión Pública, Cambio Organizacional.

\section{ABSTRACT}

The influence of New Public Management (NPM) on administrative reform in Portugal, and specifically on matters related to the introduction of greater technical rationality in public management processes, has been widely acknowledged (Mozicafredo, 2000); (Bilhim, 2008); (Rocha, 2011). Many governments of OECD member countries have undertaken identical initiatives. However, literature on administrative reform suggests institutional bureaucracies' resilience to managers' control and to change (Burns e Stalker, 1961); (Bjur e Caiden, 1978); (Bilhim 1995, 2010). The sociology of management has also helped to identify and understand the platonic image of the manager - a rational enforcer of a system for planning and controlling an organizational structure, quickly adaptable to the surroundings - transmitted by the rhetoric of technocratic ideology. This article aims to contribute to the debate on the role played by the public manager in the change in organizational culture, based on meritocracy.

Key words: Organizational Culture, Public Management, Organizational Change. 


\section{RÉSUMÉ}

L'influence du New Public Management (NPM) sur la réforme administrative au Portugal, notamment en ce qui concerne l'introduction d'une plus grande rationalité technique dans les processus de gestion publique, est amplement reconnue (Mozicafredo, 2000 ; Bilhim, 2008 ; Rocha, 2011). De nombreux gouvernements des pays de l'OCDE ont pris des initiatives identiques. Toutefois, la littérature sur la réforme administrative montre une certaine résistance des bureaucraties institutionnelles au contrôle des gestionnaires et au changement (Burns et Stalker, 1961; Bjur et Caiden, 1978 ; Bilhim 1995, 2010). Par ailleurs, la sociologie de la gestion a aidé à identifier et à comprendre l'image platonique du gestionnaire - exécutant rationnel du système de planification et de contrôle d'une structure organisationnelle, rapidement adaptable à son environnement - transmise par la rhétorique de l'idéologie technocrate. Cet article veut contribuer au débat sur le rôle du gestionnaire public dans le changement organisationnel à partir du cas de la méritocratie.

Mots-clés: Culture organisationnelle, Gestion publique, Changement organisationnel.

\section{提要}

葡萄牙实施了新的公共行政改革 New Public Management

(NPM)，引进专业技术人才到公共行政管理机构对葡国公共管理产生了很大影响 (Bilhim,1998)；(Rocha, 2001)； (Mozicafredo, 2000)。经合发展组织 (OECD) 的其他成员国政府也采取了类似的改革。然而, 在矢于行政改革的文献中人们发现官僚机构 对改革是有抵触的 (Burns e Stalker, 1961)；(Bjur e Caiden, 1978)；(Bilhim 1989)。但是，在技术精英治国的主导意识形态下，管理社会学帮助制造了一个这样的柏拉 图式的管理者形象一理性执行计划, 控制机构, 使之能最快适应政改需要 (Reed, 1989)。本论文试图探讨在能人治国的理念指导下，组织文化的转变 和管理者在此过程中所起的作用。

关键词：组织文化，公共管理，组织机构变化。

\section{Introdução}

Não é difícil aceitar o estudo da gestão como um dos processos e uma das instituições sociais mais estratégicas da nossa sociedade. Entender como os gestores, com êxito, organizam e controlam o trabalho produtivo sob grande diversidade de condições e situações constitui um desafio académico. Lançar luz sobre os processos de 
gestão, concebidos como um conjunto de mecanismos, processos e estratégias fracamente articulados, orientados pela conjugação de outras práticas respeitantes à produção de bens e serviços e representações que transformam o meio em que vivemos é, certamente, uma responsabilidade da sociologia da gestão, das organizações e do trabalho.

$\mathrm{Na}$ literatura, há quem encare, paternalisticamente, o gestor como profissional insensível, pequeno maquiavel ou prisioneiro de uma lógica estrutural que não é capaz de compreender. Neste trabalho, pelo contrário, sugere-se que as práticas de gestão apontam para a existência de redes complexas de relações que se estabelecem entre as dimensões técnica, política e ética, características do desempenho de funções de gestão. Nesta perspetiva, os gestores são profissionais de uma atividade cujo exercício exige a posse e a aplicação de saberes que os habilitam a lidar com as exigências contraditórias e as pressões impostas pela mobilização de recursos, bem como com a pressão dos esforços para manter o seu comportamento dentro dos limites prescritos ${ }^{2}$.

O gestor é o equilibrista que, sob tensão, negoceia as pressões oriundas da lógica do controlo burocrático e as do lado das exigências operacionais. O gestor público ou privado tenta manter o equilíbrio entre as preocupações da manutenção da integridade e sobrevivência da estrutura organizacional e o pragmatismo das pressões de curto prazo, destinadas a colmatar crises quotidianas e a encontrar soluções exequíveis.

Pode ser grande a dificuldade dos gestores ao procurar conciliar o conflito entre a racionalidade instrumental, indispensável à sobrevivência, e a racionalidade ontológica que exige uma fidelidade aos fins éticos que devem orientar os atos de gestão.

A retórica da ideologia tecnocrata transmite uma imagem platónica do gestor. Este não passaria de mero executor racional do sistema de planificação e controlo de uma estrutura organizacional, adaptável rapidamente à envolvente. Acontece que, quando analisamos o gestor pelo lado de dentro, vemos uma imagem muito diferente. Vemos alguém lutando para chegar a um acordo com a realidade que enfrenta e que recusa ajustar-se ou conformar-se com as categorias e princípios universais que aprendeu.

A equação do problema que trouxemos para este trabalho exige que se ultrapasse a dualidade entre a imagem pública, platónica, e a interna, centrando a discussão nos dilemas inevitáveis em que os gestores estão mergulhados e a sua luta para construir um compromisso viável entre os constrangimentos estruturais e a obstinação humana. A

\footnotetext{
${ }^{2}$ Reed, Michael (1989). The Sociology of Management, London: Harvester wheatsheaf.
} 
questão que se coloca neste trabalho consiste em saber se o gestor controla a cultura organizacional ou se, pelo contrário, é controlado por ela. É necessário melhorar a compreensão do controlo organizacional ao longo da história, devendo ser examinado o impacto que estas formas de controlo têm nas funções de gestão.

A supervisão e o controlo aparecem como questões fundamentais na história da sociologia das organizações. No entanto, os trabalhos mais recentes nesta área encorajam uma visão mais abrangente e sofisticada do controlo nas organizações mais complexas. Há uma maior sensibilidade ao contexto histórico, no qual as diferentes formas de controlo se desenvolvem, e às suas implicações na construção e na manutenção de identidades organizacionais. Estes desenvolvimentos têm dado corpo a uma "ordem de trabalhos" de investigação e a abordagens teóricas centradas no papel estratégico do poder administrativo, na ligação entre as autoridades centrais, nas burocracias e nas populações alvo, no seio das sociedades modernas. Temas que tendem a ser analisados sob a ótica das "teorias da modernidade"3.

Nestes trabalhos, o controle de gestão envolve uma tentativa deliberada de monitorar e/ou supervisionar os objetos e as pessoas, sendo exercida nas organizações formais que possuem objetivos bem explicitados, associada a uma estrutura administrativa formal que inclui acordos para a manutenção das fronteiras e as trocas entre a organização e as pessoas externas. Além disso, a modernidade compreende uma época de organizações burocráticas, as quais são fruto de um processo de racionalização da ação social, já observada por Weber ${ }^{4}$.

Há quem reforce o argumento anterior de que as organizações modernas são os mecanismos estratégicos ou dispositivos para assegurar a reprodução e/ou a transformação das estruturas institucionais centrais - a empresa, o estado burocrático, a divisão profissionalizada/perita do trabalho e o poder militar industrializado - que constituem a modernidade ${ }^{5}$.

Acresce que os grupos profissionais desempenham um papel central no desenho das formas institucionais e configurações organizacionais, que se desenvolveram nas modernas sociedades industrializadas. Neste sentido, a profissionalização é compreendida como uma parte do processo mais abrangente de burocratização. Esta, por sua vez, deve ser entendida como um movimento sustentado, no sentido de formas impessoais de

\footnotetext{
${ }^{3}$ Touraine, Alain (1998). Crítica da Modernidade, Lisboa: Instituto Piaget.

${ }^{4}$ Giddens, Anthony (2004). Sociologia, 4. ed., Lisboa: Fundação Calouste Gulbenkian.

${ }^{5}$ Dandeker, C. (1990). Surveillance, Power and Modernity, Cambridge: Polity Press.
} 
administração baseadas na difusão de sistemas de controlo de informação mais elaborados, e a sua apresentação através da aplicação de conhecimentos e técnicas periciais associadas com a profissionalização ${ }^{6}$.

Atualmente, na Administração Pública, a questão do controlo deve ser encarada sob duas perspetivas: o controlo intraorganizacional, através da lei, dos regulamentos e procedimentos técnicos e administrativo, exercido pelos dirigentes superiores e intermédios da Administração; o controlo interorganizacional exercido pela justaposição das diversas entidades que competem entre si.

A externalização de serviços, através da privatização total ou parcial do capital social das entidades empresariais do Estado ou através de outras formas onde se privilegia a concorrência entre fornecedores de serviços públicos, constitui uma forma de mudar o tipo de controlo em que a concorrência substitui o controlo interno, cujo limite é a falência das entidades mais fracas ${ }^{7}$. O campo organizacional mais propício a esta externalização e mudança do tipo de controlo é precisamente aquele que executa políticas públicas ligadas a funções do Estado que não são financiadas pelos impostos, mas por taxas, ou seja, o chamado "Estado social".

A questão a tratar neste trabalho prende-se com a clarificação das relações entre gestor/dirigente da Administração na sua função de controlador da eficiência - máximo ouput pelo mínimo input - e a cultura organizacional, enquanto sistema de normas, valores e crenças que identificam um determinado organismo público. Há culturas que maximizam e outras que minimizam a eficiência. Ora, em face desta realidade cultural simbólica, importa averiguar qual o papel do gestor/dirigente e em que medida controla ou é controlado pela cultura da organização onde se insere ${ }^{8}$.

Acresce que a meritocracia, desde de meados do Séc. XIX, é vista, quer pela administração privada, quer pela pública, como um dos traços da modernidade e, consequentemente, como garantia da eficiência organizacional. Mas, se o gestor/dirigente é controlado pela cultura organizacional, nos organismos públicos onde a meritocracia não constitui um dos traços da sua cultura, como é o caso de Portugal, será, teoricamente, possível introduzi-lo ou tratar-se-á antes de um mito?

\footnotetext{
${ }_{7}^{6}$ Bilhim, João (2009). Ciência da Administração, 2. ed., Lisboa: Universidade Aberta

7 Bilhim, João (2000). "Gerir a Administração Pública como uma Empresa". In Reforma do Estado e Administração Pública Gestionária, Lisboa: ISCSP.

${ }^{8}$ Shein, Edgar (1985). Corporate Culture and Leadership, San Francisco: Jossey-Bass.
} 


\section{O Gestor/Dirigente e o Controlo da Cultura Organizacional}

A cultura é intangível, implícita, dada como certa, e cada organização desenvolve pressupostos, compreensões e regras, que guiam o comportamento diário no local de trabalho. Até aprenderem essas regras, os novos empregados não são aceites como membros plenos da organização. Daí que as transgressões resultem em desaprovação e penalizações e a conformidade às regras se torne a base primária da compensação e da mobilidade ascendente ${ }^{9}$.

Assim, tomando a cultura como variável, enquanto normas, valores e crenças subjacentes à vida organizacional, que resultam de processos de socialização ou tomando a cultura como um sistema de ideias e significados partilhados, formas expressivas e manifestações da consciência humana, somos sempre confrontados com este dilema do controlo do gestor ou da cultura.

Acontece que, para resolver esta questão, será necessário equacionar outra que é prévia: as organizações possuem apenas uma ou várias culturas? E se possuem apenas uma cultura, qual o papel das subculturas?

A cultura dominante expressa as normas, os valores e as crenças essenciais a toda a organização e que são partilhados por um número maior ou menor de membros. Quando se fala de cultura está-se a referir à dominante, à macro visão que confere à organização a sua identidade. Salienta-se que, em organizações complexas e com marcada estratificação social, os grupos em presença reportam-se a diferentes culturas e nelas baseiam os seus jogos e estratégias de poder e influência, como parecem ser os organismos públicos.

Num modelo pluralista, que labore a partir do reconhecimento das dicotomias internas e valorize as questões políticas, a cultura pode atuar como suporte das estratégias intergrupais. Analisar as relações sociais no contexto organizacional exige refletir sobre o processamento, nesse mesmo espaço, de relações de poder. Para Teixeira Fernandes ${ }^{10}$, toda a estrutura da ação coletiva se organiza como sistema de poder. $O$ poder está presente em toda a instância do quotidiano e atinge todo o tipo de interações sociais, do mais simples ao complexo. As relações de poder assentam na

\footnotetext{
${ }^{9}$ Bilhim, João (1988). Cultura Organizacional do INESC. Dissertação de mestrado - Instituto Superior de Ciências Sociais e Política, Lisboa.

10 Fernandes, A. Teixeira (1998). Os Fenómenos Políticos: Sociologia do Poder, Porto: Edições Afrontamento.
} 
assimetria instrumental de competências profissionais e no capital intelectual presente nos diversos grupos socioprofissionais.

Hoje, reconhece-se que as organizações são fenómenos sociais intrinsecamente políticos, enquanto responsáveis pela criação da ordem e da autoridade destinadas a dirigir pessoas, que possuem interesses muitas vezes opostos e conflituantes.

É suposto, formalmente, a organização ser gerida pela racionalidade da relação entre meios e fins, recursos utilizados e resultados obtidos. Por isso, esconde-se ou ignora-se esta atividade política e o conflito de interesses, fazendo de conta que os mesmos não existem. Isto leva a considerar o termo "política" ou "conflito de interesses" como palavras a evitar.

Assim, as organizações, tal como os governos, usam sistemas de "regras" como meios para criar e manter a ordem entre os seus membros. A análise política quer na gestão privada, quer, particularmente, na gestão pública e na administração pública, fornece uma boa ajuda para a análise interior destas organizações.

Bourdieu ${ }^{11}$ defende que o habitus varia em função da posição que o indivíduo ou grupo de indivíduos ocupa no campo. O domínio de recursos, poderes ou capitais específicos está na base da posição que o indivíduo ou grupo de indivíduos ocupam no campo social.

Faz, assim, todo o sentido encarar as organizações públicas como possuindo diversas culturas, nomeadamente, as específicas das categorias socioprofissionais nomeadamente das carreiras do regime especial e das carreiras do regime geral, em que se verificam diferenças acentuadas entre as culturas organizacionais dos assistentes técnicos, dos administrativos, dos técnicos superiores e dos dirigentes superiores e intermédios. Estes grupos socioprofissionais possuem mundividências diferentes e assumem-se como formas de pensar, sentir e agir diferentes, funcionando como grupos de interesse setoriais em competição por recursos escassos.

Todavia, se uma organização pública complexa é povoada por uma pluralidade de culturas profissionais, departamentais, as regionais, entre outras, como é que se não desintegra, como é que o princípio da coesão se impõe ao da especialização e diversificação? Toda a organização sem uma cultura que permita aos seus membros uma interpretação comum do que seja ou não adequado fazer, não sobrevive e desintegra-se.

\footnotetext{
${ }^{11}$ Bourdieu, Pierre (1997). Razões Práticas sobre a Teoria da Ação, Oeiras: Celta Editora.
} 
É, precisamente, este carácter de partilha de compreensão, que confere à cultura a capacidade de guiar e dirigir os comportamentos.

Para coesão das culturas organizacionais existentes no interior de um organismo público e dos grupos de interesse em presença, as organizações possuem um recurso global e um sistema de autoridade formal, estruturantes dos comportamentos e das relações de trabalho que é a hierarquia. É que as estratégias setoriais de cada cultura, na luta por recursos escassos, ficam suspensas quando é atingido um ponto tal de tensão que, se qualquer dos atores em presença prosseguir, põe em risco a sobrevivência do todo e das respetivas partes organizacionais. Nesse pico máximo da tensão da dinâmica organizacional, há o recurso à hierarquia e aos gestores/dirigentes.

Entre os traços culturais que identificam cada cultura no interior dos organismos públicos existe um que funciona como uma espécie de cimento integrador de toda a organização e que é o produto da ação e intervenção de líderes formais e informais que permanentemente definem, não tanto uma realidade unitária e consensual, mas um sistema de ação concreto, com conflitos de interesse e jogos de poder. É este traço cultural que permite a existência da coesão organizacional indispensável à sobrevivência e condição da eficiência.

Parece haver a consciência mais ou menos generalizada que, para certos picos de tensão na dinâmica organizacional, se tem de recorrer à negociação e ao recurso à hierarquia, através do recurso a líderes formais. Quando surgem problemas e dificuldades, é a eles que se atribuem responsabilidades, sejam eles ou não a sua causa. Há, todavia, que notar que o papel das coligações dominantes não é passivo ou reativo face às envolventes, pois as organizações também têm influência na sua transformação e constituição.

Quando emergem os conflitos e se não dispõe de racionalidade completa para os resolver, é inevitável o recurso ao poder. Por outras palavras, como não há processo de racionalizar a dissensão, é a força política dentro das coligações quem determina os critérios e as preferências que devem prevalecer. Ora, esse traço de cultura, presente, em graus diferentes, em cada cultura organizacional que integra um organismo público, joga um papel crucial na manutenção de cumplicidades na estrutura orgânica que está na base da coesão e, consequentemente, da sobrevivência organizacional.

Da análise desenvolvida pode concluir-se que o gestor/dirigente de um organismo público controla e é controlado, simultaneamente, pela (s) cultura (s). Os gestores controlam a sua própria cultura que, tal como as restantes, faz parte do organismo público 
em causa e é entre os traços da cultura dos gestores/dirigentes que se encontram os processos que justificam a sua profissão, nomeadamente, o domínio dos instrumentos da eficiência organizacional. Todavia, na arena política organizacional, terão de negociar com as restantes culturas e concertar os seus dissensos e, nesse ponto, são controlados, de alguma forma, por esta rede de relações sociais e teia de poderes onde se inserem e que constitui a dinâmica organizacional.

\section{A Gestão do Mérito na Administração Pública}

Hoje assume-se a existência de duas orientações distintas na teoria da administração pública: uma primeira, que tende a encarar a administração pública como parte do processo de governo e, assim, representa uma parte da teoria política; uma segunda, que salienta os aspetos comuns às organizações públicas e privadas sendo, nesta perspetiva, a administração pública uma parte da teoria organizacional mais vasta.

A primeira perspetiva, que procura distinguir o gestor público do privado pela participação daquele no processo de governo e, consequentemente, nas políticas públicas e na alocação de valores na sociedade, é a mais antiga. Nesta visão, o gestor público é avaliado pelo mesmo padrão dos restantes atores do processo político. Salientase que a atuação dos órgãos e agentes administrativos, de acordo com o plasmado no artigo 266 da Constituição da República Portuguesa, está marcada pela prossecução do interesse público, com respeito pelos princípios da igualdade, proporcionalidade, justiça, imparcialidade e boa-fé.

Em contraste com esta abordagem, outros autores defendem que 0 comportamento dos indivíduos no interior das organizações públicas ou o próprio comportamento das organizações em si mesmo não se distingue grandemente dos privados. Esta abordagem genérica da análise organizacional deu oportunidade ao desenvolvimento de muitos estudos interdisciplinares, oriundos da administração pública, da privada, da sociologia e da psicologia das organizações, entre outros campos das ciências sociais e comportamentais. Para esta perspetiva, as preocupações básicas da gestão são idênticas, quer se trate de empresas privadas ou de organismo e agências públicos.

O ponto que liga a todos é a preocupação com a meritocracia, mas esta preocupação é tão antiga como o mandarinato, instituído na China antiga. Os mandarins dividiam-se em duas categorias: a civil e a militar. Cada uma destas categorias dividia-se em nove graus, subdividindo-se cada um destes em duas classes: a dos grandes 
mandarins e a dos mandarins ordinários. O acesso a esta classe privilegiada era feito por concurso, depois de obtidos diferentes graus de conhecimento, progressivamente mais exigentes. As promoções na carreira eram obtidas por mérito.

Nos tempos modernos, não é de estranhar que esta orientação da atuação dos gestores remonte aos primórdios da ciência da administração, tendo, muito cedo, aparecido nos EUA, a pautar as relações entre a ciência e a gestão privada. Como sua consequência deu-se a emergência dos conhecidos "princípios científicos" destinados a aumentar a produtividade empresarial ${ }^{12}$.

Acresce que esta preocupação pela meritocracia surge logo a seguir no setor público; Woodrow Wilson $^{13}$ defende a separação entre políticos e burocratas e, consequentemente, afirma que estes devem ocupar as posições de poder no interior da estrutura organizacional de acordo com o seu mérito. Já no séc. XX, Max Weber ${ }^{14}$ atribuiu particular ênfase à meritocracia, ao referir, na caraterização da burocracia formal, que a seleção dos trabalhadores faz-se com base nas qualificações técnicas e que as mesmas podem ser testadas através de exames ou diplomas onde se certifique a posse da formação técnica dos candidatos.

A meritocracia tem acompanhado a história da administração pública e, recentemente, a sua importância foi reforçada pela cartilha reformista da nova gestão pública New Public Management (NPM). O aspeto mais curioso é que, assumindo-se a reforma promovida pela NPM como anti weberiana, não deixa de comungar com Weber a importância atribuída à meritocracia.

Acontece que a seleção com base no mérito tem sido valorizada e aceite, ao longo dos tempos, como sinal de modernidade, garantia ética, baluarte contra a corrupção e garantia de imparcialidade na gestão das pessoas no sector público.

Para a sociologia contemporânea, a meritocracia corresponde a um sistema em que as posições sociais são preenchidas com base no mérito individual e não em virtude de critérios como a riqueza, o sexo, a origem social ou a cor do partido político onde se milita $^{15}$.

\footnotetext{
12 Bilhim, (2009). Op. Cit.

${ }^{13}$ Wilson, Woodrow, (1887). "The Study of Administration”. In Political Science Quarterly, n.2, v.2, p. 197222.

${ }^{14}$ Weber, Max. (1978). Economy and Society, Berkley: University of California Press.

15 Bilhim, João (2012). "O Mérito nos Processos de Seleção da Alta Direção da Administração Pública Portuguesa: mito ou realidade”. In Sequência: Estudos Jurídicos e Políticos, v. 33, n. 65, p. 57-78.
} 
$\mathrm{Na}$ análise da literatura atual da administração pública, os termos meritocracia/ meritocrático/ mérito, numa ligeira análise de conteúdo, aparecem, quer na literatura científica, quer nos relatórios profissionais dos práticos, quer ainda nas recomendações de diversos organismos internacionais como a OCDE/PUMA e o Banco Mundial.

Ora, esta preocupação com a meritocracia no setor público, embora tenha sofrido altos e baixos, nunca deixou de estar no centro do ensino, da investigação e das práticas e processos do setor público. Por isso, impõe-se a pergunta: por que razão esta preocupação se encontra atualmente em alta?

A razão prende-se com o facto de o paradigma administrativo da Europa do sul colocar o enfoque da ação administrativa na interpretação e aplicação da lei e não na eficiência, tal como é tradição da cultura administrativa anglo-saxónica e do norte da Europa.

A resistência que, em Portugal, se está a sentir na aplicação do sistema integrado de avaliação do desempenho na Administração Pública (SIADAP) como instrumento de gestão do mérito, patenteia bem em qual destas duas culturas administrativas se encontra o País. É cero que há bolsas de excelência na introdução desta nova postura comportamental, mas, em geral, a resiliência à manutenção da ascensão na carreira com base na antiguidade e não no mérito demonstrado, expressa este caldo de cultura organizacional.

\begin{tabular}{|c|l|l|}
\hline \multicolumn{1}{|c|}{ Critérios } & \multicolumn{1}{|c|}{$\begin{array}{c}\text { Europa do Sul } \\
\text { Objetivos }\end{array}$} & $\begin{array}{l}\text { Guropa do Norte e Anglo- } \\
\text { órgão }\end{array}$ \\
\hline Critério de sucesso & $\begin{array}{l}\text { Fazer o que e como a lei } \\
\text { prescreve. }\end{array}$ & $\begin{array}{l}\text { Atingir objetivos quantificados } \\
\text { mensuráveis }\end{array}$ \\
\hline Uso de recursos & $\begin{array}{l}\text { Recursos abundantes; a } \\
\text { eficiência é secundária }\end{array}$ & $\begin{array}{l}\text { Recursos escassos; a } \\
\text { eficiência é essencial }\end{array}$ \\
\hline Tipo de estrutura & $\begin{array}{l}\text { Mecanicista, rígida e hierarquia } \\
\text { forte e longa }\end{array}$ & $\begin{array}{l}\text { Flexível, achatada, maior } \\
\text { delegação }\end{array}$ \\
\hline Papel do dirigente & $\begin{array}{l}\text { Passivo. Intérprete e executor de } \\
\text { regulamentos e procedimentos }\end{array}$ & $\begin{array}{l}\text { Ativo. Protagonista; assume } \\
\text { risco controlado. }\end{array}$ \\
\hline João Bilhim. Elaborado a partir da literatura comparada e do conhecimento empírico da situação em Portugal
\end{tabular}


Importa salientar uma contradição significativa da cartilha da reforma preconizada pela NPM. A NPM afirma-se como combatente contra a burocracia weberiana, mas não deixa de adotar o seu conceito de mérito e impor a sua prática às diversas administrações públicas, independentemente da cultura dos povos no seio da qual tais administrações existam $^{16}$.

Atualmente, as organizações públicas estão confrontadas com o impacto de duas ondas diferentes. As práticas atuais já não correspondem a qualquer modelo do passado, mas ainda não se encontram integradas e unificadas numa nova teoria. Muita coisa se passou nestes trinta anos após a queda do muro de Berlim em 1989: novo paradigma económico: "nova escolha pública"; transformações geopolíticas; globalização; emergência da China, Índia, Brasil; impacto das TI em geral.

Descobriu-se a importância para qualidade de vida dos cidadãos da boa governação e do papel interdependente dos setores - privado, público e sociedade civil. Tomou-se consciência que não pode haver boa governação sem que haja um bom governo, um serviço público eficaz, e instituições públicas tão produtivas quanto as privadas.

O Século XX legou-nos uma teoria e práticas de administração pública robustas e resilientes à mudança. Todavia, a resiliência precisa de se adaptar, ser contingencial às novas circunstâncias e ao imprevisto. Estes trinta nos foram ricos em novas experiências, promotoras de um Estado mais transparente, flexível, com recurso a privatizações, descentralização, desregulamentação e, em particular, na promoção de organizações públicas eficientes e meritocráticas.

Portugal encontra-se num ponto do processo de mudança caraterizado por já não ser uma coisa, mas ainda não ser outra, encontra-se no processo de transição entre o paradigma clássico jurídico e o novo paradigma gestionário onde a meritocracia deve desempenhar um papel crucial na cultura organizacional dos gestores/dirigentes dos organismos públicos.

Parece existir, entre os académicos que ensinam e os práticos que trabalham nas organizações públicas, uma espécie de crença generalizada que de alguma forma vai passando de geração em geração ao longo dos tempos sobre uma administração pública ideal onde a corrupção seria totalmente derrotada e o mérito seria a regra na ocupação de

${ }^{16}$ Pollit, C; Bouckaert, G. (2004). Public management reform: a comparative analysis, Oxford: Oxford University Press. 
todos os cargos e funções na estrutura do Estado. Aliás, a retórica dos partidos políticos, em democracia, ajuda, significativamente, a alimentar esta crença, quer em momentos específicos como são os eleitorais, quer, mais tarde, nas formas de fazer oposição parlamentar.

Ora, se é certo que Max Weber, no conceito de burocracia como tipo ideal, prescrevia a meritocracia como consequência da evolução social, não é menos certo que o modelo gestionário, desde a década de oitenta do século passado, combatendo o modelo burocrático weberiano de organização do Estado e da Administração Pública, coloca a urgência da introdução de sistemas meritocráticos como um dos pontos essenciais da sua cartilha.

Por isso, não pode deixar de ser colocada a seguinte questão: se as organizações públicas portuguesas adotaram o modelo weberiano e não apresentam resultados em matéria de meritocracia ao ponto da NPM, embora com uma postura teórica anti weberiana, continuar a insistir que esta caraterística do tipo ideal de Max Weber precisa de ser atingida, parece constituir uma contradição.

Com efeito, nas quatro últimas décadas, assistiu-se a uma crítica generalizada ao desempenho organizações públicas, acusadas de fidelidade ao modelo weberiano e, consequentemente, de estarem em contraciclo com a evolução social, impondo-se, por isso, a modernização administrativa cujo ponto central seria a introdução do mérito.

Muitas vozes denunciaram este estado de coisas, sublinhando aspetos tais como: má imagem dos serviços prestados; baixa qualidade; custos excessivos; burocracia e centralização; opacidade aos olhos do cidadão; perceção de que os dirigentes não resolvem os problemas dos cidadãos, mas a sua própria carreira; corrupção; fraca produtividade; falta de recursos qualificados; desmotivação de funcionários; ausência de controlo de custos; ausência de pensamento estratégico e visão; fraca gestão; ausência de um sistema meritocrático.

Todos os interessados em redor da Administração, desde os sindicatos, empresários, órgãos de comunicação social, consultores, partidos políticos até ao público em geral, pressionaram os governos para que estes reformassem a Administração Pública em virtude de esta ter sido construída com base em princípios errados da burocracia de Max Weber, precisando de ser reinventada e de renovar as suas instituições. 
A cartilha da NPM, que Portugal, entre os muitos países da OCDE, está adotando, compreende medidas tais como: cortes orçamentais, privatizações, rutura entre o financiamento e aprestação, contratualização, vouchers ou cheques diretos aos cidadãos, preocupação mais com o cliente/utente/usuário do que com o cidadão, fomento da concorrência entre prestadores (privado/ público e público/público), gestão flexível, uma reedição da dicotomia de Wilson quanto à relação entre políticos e burocratas, descentralização e desconcentração de serviços, agenciamento, fomento das práticas de governo eletrónico, maior regulação e menor prestação pelo Estado, avaliação do desempenho e recrutamento por mérito.

Importa reconhecer que este elenco de novos princípios e processos de gestão pública não deixam de aparentar um conjunto desgarrado e avulso de medidas, embrulhadas por vezes numa estratégia vaga de melhoria da qualidade dos serviços e de "fazer mais com o mesmo orçamento ou fazer o mesmo com menos custos", lançando mão de capacidade instalada escondida ou do contributo da inovação tecnológica.

Quanto à meritocracia, que integra o "tipo ideal" de burocracia de Weber e constitui recomendação da cartilha de reforma da NPM, será que estará ela ausente da cultura das instituições públicas? A meritocracia não parece estar presente na expressão das práticas quotidianas da ação social destas culturas organizacionais, mesmo na dos dirigentes, dada a resistência encontrada pelos Governos na introdução de práticas meritocráticas. Todavia, a meritocracia parece estar bem presente nos valores destas culturas.

Parece existir uma contradição para cuja compreensão se poderá recorrer ao conceito de cultura real e cultura ideal de Malinowski. Tudo indica que o valor da meritocracia integre, em graus diferentes, as diversas culturas presentes no interior das organizações públicas. Atualmente, já nem os sindicatos assumem que não seja a meritocracia um valor, circunscrevendo-se a questionar os processos meritocráticos em concreto, ou seja, as práticas.

Para esta ausência da meritocracia das práticas organizacionais públicas, são aduzidos muitos e diferentes argumentos, tais como: a dificuldade da mensuração do trabalho não repetitivo, ou seja, técnico, o fomento de um certo darwinismo social que abandonaria os mais fracos à sua sorte, a falta de mecanismos que assegurem a equidade relativa entre avaliadores e organizações, a arbitrariedade do decisor, a subjetividade do processo, entre outros. 
Salienta-se que, tal como acontecia entre os trobiandeses, observados por Bronisław Malinowski ${ }^{17}$, a exogamia era apresentada como grande valor, mas a endogamia não deixava de ser altamente apreciada intramuros, ou seja, a meritocracia é assumida como politicamente correta pelas culturas organizacionais mas as práticas expressam simpatia pela velha cunha e pela antiguidade como critério de progressão na carreira. A questão que se coloca agora ao gestor/dirigente é a de como mudar as práticas e os processos de trabalho.

\section{O Gestor Público e a Mudança Organizacional}

A cultura dirigente das organizações públicas integra dois grandes grupos dirigentes superiores e intermédios, ambos de 1. e $2^{\circ}$ grau. Porém, nas organizações públicas de missão, atribuições e competências com caráter mais operacional, o chefe de divisão, dirigente intermédio de 2. grau, desempenha o papel de chefia direta e superintende na produção, uma vez que foram extintos os chefes de repartição e de secção que tradicionalmente integravam o núcleo das chefias diretas.

A função dos dirigentes consiste na organização e controlo dos processos de trabalho e de produção de bens e serviços, quer se trate do grupo dos dirigentes de topo da Administração, dos dirigentes intermédios de 1. grau, o diretor de serviços, que implementam a política do organismo, quer se trate da chefia direta, o chefe de divisão.

$\mathrm{Na}$ administração central do Estado, o diretor geral ou presidente de instituto público, à medida que é selecionado com base no mérito e não na escolha política do Governo, tende a ser tido como o representante do equilíbrio de interesses entre o Governo (políticos eleitos), os trabalhadores da administração, integrados em carreiras do regime geral ou do regime especial e os cidadãos. Os gestores de topo, selecionados com base no mérito, passam a desempenhar um papel crucial na avaliação do equilíbrio de interesses divergentes envolvidos nos processos de tomada de decisão.

À medida que o processo de tomada de decisão vai progressivamente abandonando o caráter programado típico do clássico paradigma jurídico (só se faz o que a lei prevê) e entrando no modelo gestionário, marcado pela eficiência, eficácia, equidade

\footnotetext{
${ }^{17}$ Malinowski, B. (1975). Uma Teoria Científica da Cultura, Rio de Janeiro: Zahar.
} 
e ética, o fator dominante do papel dos gestores/dirigentes é a interação entre as lutas pelo poder e os debates culturais e ideológicos acerca do futuro da organização

Os processos de mudança podem seguir orientações diversas, com pressupostos teóricos e modelos implícitos diferentes. São de salientar os seguintes: a mudança como um processo de evolução geral; de adaptação; terapêutico; revolucionário; a ser gerido. Têm, ao longo do tempo, sido defendidos diversos mecanismos de gestão da mudança.

Kurt Lewin ${ }^{18}$ definiu o mecanismo da gestão da mudança com base nas três fases seguintes: descongelamento - alteração do estado presente de equilíbrio, responsável pela sustentação dos atuais comportamentos e atitudes. Este processo deve tomar em atenção as ameaças que a mudança poderá suscitar e a necessidade de motivar os que integram o novo processo; mudança - desenvolvimento de novas respostas, com base em nova informação e congelamento- estabilização da mudança pela introdução de novas respostas.

Na perspetiva de Lewin, para se obter uma mudança bem-sucedida há que seguir os seguintes passos: examinar as forças que se opõem ou apoiam a mudança; diagnosticar o peso específico de cada uma; fortalecer as forças favoráveis e enfraquecer as desfavoráveis. Neste processo, os gestores/dirigentes identificam o problema que necessita de mudança; fixam objetivos; definem o estado futuro ou das condições organizacionais desejadas após a mudança; gerem o processo de transição. A gestão da mudança não é um processo linear. Por isso, é necessário prestar atenção constante ao todo organizacional.

No caso concreto da introdução da meritocracia nas práticas e processos de gestão é indispensável que a ausência do mérito nos processos de gestão do trabalho gere insatisfação havendo tanta consciência da necessidade de mudar como dos riscos em não mudar. Acresce que, no processo de mudança, as pequenas ações poderão ter um efeito catalítico fundamental.

Para Pettigrew $^{19}$, a compreensão do problema da mudança em termos estratégicos exige a análise em conjunto do contexto, do conteúdo e do processo da mudança, sem valorizar mais um elemento do que os restantes.

Um processo de mudança por parte do topo da hierarquia poderá seguir os seguintes seis passos: estimular os trabalhadores e as chefias intermédias para a

\footnotetext{
${ }^{18}$ Lewin, Kurt (1951). Field Theory in Social Science, New York: Harper \& Row.

${ }^{19}$ Pettigrew, A. (1985). The Awakening Giant: Continuity and Change in ICI, Oxford: Basil Blackwell.
} 
mudança, através da análise conjunta dos problemas existentes que afetam a organização; desenvolver uma visão partilhada sobre o futuro; incitar o consenso acerca desta nova visão, fomentando a coesão; derramar a revitalização por todos os departamentos, sem pressionar do topo; oficializar a revitalização através de políticas formais, sistemas e estruturas; controlar e ajustar estratégias, em resposta aos problemas do processo de revitalização.

$\mathrm{Na}$ sequência de uma investigação sobre a gestão da mudança, Pettigrew e Whipp $^{20}$ concluíram que a eficácia da mudança estratégica exige: a construção de um clima recetivo à mudança (o que implica justificar a razão pela qual esta é necessária); a construção da capacidade de mudar (antes de introduzir a mudança); o estabelecimento de uma agenda da mudança, (que estabeleça a direção do negócio, a visão necessária e os seus valores implícitos). Sugerem ainda os autores as seguintes medidas secundárias para apoiar a intervenção estratégica: a transformação das intenções em componentes de ação; a atribuição de responsabilidades por estas componentes a gestores da mudança que atuarão no quadro das estruturas dos diversos níveis da organização; o ajustamento da função compensação, o sistema de remuneração, bem como dos mecanismos de comunicação aos objetivos da mudança.

Para Robert Quinn ${ }^{21}$, a mudança profunda exige uma nova maneira de pensar e de se comportar na organização. É mais ambiciosa na sua finalidade, descontínua em relação ao passado e geralmente irreversível. A mudança profunda rompe com os padrões de ação do quotidiano e envolve um assumir de riscos e uma certa perda de controlo.

Segundo Quinn a mudança profunda ocorre com o processo transformacional, o qual possui quatro fases distintas: iniciação; incerteza; transformação; rotina. Na fase da iniciação, desenvolve-se a visão do que se quer a longo prazo, avocando o risco da iniciativa. Na fase da incerteza, os participantes comprometem numa ação intensa e de experimentação intuitiva. Na fase transformacional, a aprendizagem intuitiva e obtida através da experimentação conduz a um novo paradigma. Na fase da nova rotina, instalam-se as novas práticas.

Encontra-se nas mãos dos gestores públicos esta capacidade instrumental racional e simbólica, para, conjugando o planeamento com a improvisação e a negociação de

\footnotetext{
${ }^{20}$ Pettigrew, A.; Whipp, R. (1991). Managing Change for Competitive Success, Oxford: Blackwell.

${ }^{21}$ Quinn, Robert (1996). Deep Change, San Francisco: Jossey-Bass.
} 
interesses divergentes, estabelecer o rumo do futuro das organizações públicas. Esse futuro não é estabelecido apenas pelo grupo dos gestores/ dirigentes; nele, são parceiros as restantes culturas organizacionais internas, os diversos partidos políticos e os cidadãos organizados, por sua vez, em diversos e conflituantes grupos de interesse.

Por exemplo, os gestores de topo de um organismo do sistema público de segurança social, ao introduzirem os mecanismos de meritocracia, previstos na lei, como seja o SIADAP ou o sistema de recrutamento e seleção através da Comissão de Recrutamento e Seleção para a Administração Pública (CReSAP), não podem ignorar que entre os cidadãos e entre os seus trabalhadores há visões diferentes sobre o que deverá ou não ser este organismo no futuro.

A meritocracia parece ser assumida em geral como um valor democrático nas sociedades abertas e globais. Todavia, as práticas organizacionais, parecem estar ainda afastadas da aplicação deste valor e para que a mudança tenha lugar parece indispensável o papel dos gestores/dirigentes. O segredo permanece na capacidade dos gestores adotarem ou não uma estratégia ganhadora na implementação do mérito nas práticas de gestão pública.

As dificuldades que ainda perduram, atualmente, ligam-se ao facto da cultura dos gestores/dirigentes da Administração Central do Estado se encontrar mais marcada pelo paradigma jurídico do que pelo novo paradigma gestionário. No paradigma jurídico, 0 conteúdo da função de gestão está contino na interpretação e aplicação da lei. Assim, a meritocracia, sendo imposta por via da lei, perde o seu impulso e força dinâmica de instrumento de gestão que possui no setor privado.

A implementação de um processo de mudança destinado a introduzir na Administração Central do Estado uma política meritocrática será sempre mais espinhosa que seria o mesmo processo no setor privado. Em primeiro lugar, porque a cultura dos gestores/dirigentes na Administração Central do Estado parece valorizar menos a meritocracia que a cultura dos gestores do setor privado.

Nas muitas entrevistas realizadas com dirigentes superiores e intermédios na Administração a expressão mais usada é "isto é muito diferente do setor privado" e, quando confrontados com a meritocracia, facilmente fica a impressão que esta é aceite apenas porque faz parte do politicamente correto. Não parece constituir ainda um valor com idêntica força ao que se verifica no setor privado. Assim, se ainda não constitui um 
valor enraizado no sistema de valores da cultura dos dirigentes, maior será a dificuldade em vir a expressar-se nas práticas quotidianas.

Outra dificuldade revelada pela Administração Central do Estado nos processos de mudança prende-se com o facto de a sua estrutura ter sido pensada para ser resiliente e resistir a processos de mudança. Por força disto, os dirigentes revelam fraca experiência, competência e capacitação para gerir tais processos.

Todavia, militando contra esta rigidez verificamos na literatura que o conceito de governação se assumiu como sendo preferível ao de administração; os princípios da administração sendo apenas hipóteses e não factos; a administração lidando com valores e ética em toda a sua intervenção; os dirigentes jogando um papel importante na afirmação da democracia; e a Administração dependendo do contexto interno e externo. Parece haver uma contradição acentuada entre o que se faz e o que deve ser feito que está a provocar a necessidade urgente de mudanças.

Em nosso entender, a Administração Central do Estado encontra-se no ponto de descongelação a que faz referência Kurt Lewin. Já não é o que foi, mas ainda não é o que se deseja, (neste futuro pode haver expectativas opostas), ou seja, está num estado de certa anomia, posiciona-se como um hífen. Ainda não vive a meritocracia como um valor e uma prática de gestão, mas já se envergonha da seleção com base na escolha política, na cunha e na visão da antiguidade como um posto.

\section{Notas Conclusivas}

As reformas da Administração, expressas através da cartilha da NPM, têm acarretado a fragmentação dos serviços e das estruturas organizacionais da administração tradicional e a sua aplicação teve como consequência o acento colocado mais na gestão de risco e menos na prudência e lei, mais na competição e menos na cooperação e confiança, mais na eficiência e menos na equidade, mais na proliferação de organismo com naturezas jurídicas diversas e menos no holismo dos organismos públicos, mais no direito privado e menos no direito administrativo

Acresce que, a literatura sobre a reforma administrativa é rica em referências relativas à resiliência ou resistência à mudança das instituições, em especial quando as reformas põem em causa as práticas, os processos e os procedimentos culturalmente instituídos. A cultura organizacional, vista como o conjunto de normas, valores e crenças, 
na sua dimensão mais profunda, condiciona os traços culturais mais superficiais, como as rotinas, os processos, as práticas e os sistemas de gestão.

A cultura dos gestores parece possuir este traço uma vez que a meritocracia constitui um dos processos de controlo da sua profissão. Todavia, na cultura dos gestores públicos/dirigentes a meritocracia parece ser assumida apenas como o politicamente correto.

Verifica-se, no entanto, em todas as culturas presentes no interior das organizações públicas, uma apetência para aceitar, pelo menos idealmente, a seleção dos profissionais para ocuparem diversas posições na estrutura com base no mérito como um valor.

Acontece que os estudos de terreno não evidenciam estas práticas, como artefacto mensurável, porque, como ficou problematizado neste trabalho, há uma diferença acentuada entre a cultura ideal e a cultura real. Pode o valor estar presente na cultura ideal, mas ausente nas práticas e processos.

Em face disto, parece que a função sociológica do gestor/dirigente assume um papel de uma importância crítica neste processo de mudança organizacional. Só os gestores/dirigentes poderão fazer com que as reformas introduzidas em Portugal, através da alteração do estatuto do pessoal dirigente dos serviços e órgãos da administração central, local e regional do Estado, com a Lei n. 64/2011, de 22 de dezembro, se expressem no quotidiano como uma artefacto cultural caraterístico das diversas culturas presentes nas organizações públicas.

O valor do mérito, que parece fazer parte dos traços culturais ideais das diversas culturas organizacionais, só passará a constituir uma manifestação concreta através do esforço de concertação e negociação que constitui o quotidiano da função do gestor público.

\section{Referências}

Bilhim, João (1988). Cultura Organizacional do INESC. Dissertação de mestrado, Instituto Superior de Ciências Sociais e Política, Lisboa.

(1995). "Para uma Teoria da Gestão da Mudança Estratégica". In Estratégia e Planeamento na Gestão e Administração Pública, Lisboa: ISCSP, p. 221-235. 
(2000). "Gerir a Administração Pública como uma Empresa". In Reforma do Estado e Administração Pública Gestionária, Lisboa: ISCSP, p. 75-85.

(2008). Teoria organizacional: estruturas e pessoas, 6. ed., Lisboa: ISCSP.

(2009). Ciência da Administração, 2. ed., Lisboa: Universidade Aberta.

(2010)."Mudança Organizacional”. In Costa, Silvia Generali da; Vieira, Leandro; Rodrigues, Jorge Nascimento (Orgs.). Gestão da Mudança: Explorando o comportamento organizacional, São Paulo, Atlas, p 5-19.

(2012). "O Mérito nos Processos de Seleção da Alta Direção da Administração Pública Portuguesa: mito ou realidade". In Sequência: Estudos Jurídicos e Políticos, v. 33, n. 65 , p. $57-78$.

Bjur, W. E.; Caiden, G. E. (1978). "On Reforming Institutional Bureaucracies". In International Review of Administration Sciences, n.44, p. 359-65.

Bourdieu, Pierre (1997). Razões Práticas sobre a Teoria da Ação, Oeiras: Celta Editora.

Burns T.; Stalker G. M. (1961). The Management of Innovation, London: Tavistock.

Dandeker, C. (1990). Surveillance, Power and Modernity. Cambridge: Polity Press.

Fernandes; A. Teixeira (1998). Os Fenómenos Políticos: Sociologia do Poder, Porto: Edições Afrontamento.

Giddens, Anthony (2004). Sociologia, 4. ed., Lisboa: Fundação Calouste Gulbenkian

Lewin, Kurt (1951). Field Theory in Social Science, New York: Harper \& Row.

Malinowski, B. (1975). Uma Teoria Científica da Cultura, Rio de Janeiro: Zahar.

Mozicafredo, Juan (2000). "O Papel do Cidadão na Administração Pública". In Reforma do Estado e Administração Pública Gestionária, Lisboa: ISCSP, p. 23-35.

Pettigrew, A. (1985). The Awakening Giant: Continuity and Change in ICI, Oxford: Basil Blackwell.

Pettigrew, A.; Whipp R. (1991). Managing Change for Competitive Success, Oxford: Blackwell.

Pollit, C. (2003). The Essential Public Manager, London: Open University Press.

Pollit, C; Bouckaert, G. (2004). Public Management Reform: A comparative Analysis, Oxford: Oxford University Press.

Quinn, Robert (1996). Deep Change, San Francisco: Jossey-Bass.

Reed, Michael (1989). The Sociology of Management, London: Harvester wheatsheaf. 
Rocha, J. A. O. (2011). Gestão Pública: teorias, modelos e práticas, Lisboa: Escolar editora

Shein, Edgar (1985). Corporate Culture and Leadership, San Francisco: Jossey-Bass.

Touraine, Alain (1998). Crítica da Modernidade, Lisboa: Instituto Piaget.

Weber, Max. (1978). Economy and Society, Berkley: University of California Press.

Wilson, Woodrow, (1887). "The Study of Administration". In Political Science Quarterly, v.2, n.2, p. 197-222.

Recebido para publicação em fevereiro de 2013.

Aprovado para publicação em março de 2013. 